\title{
Type 2 diabetes in young Indigenous Australians in rural and remote areas: diagnosis, screening, management and prevention
}

Peter Azzopardi MB BS, MEpi, FRACP Research Fellow'.2

Alex D Brown BMed, MPH, PhD Executive Director

Paul Zimmet MD, PhD, FRACP Director Emeritus

Rose E Fahy MB BCh, FRACP, MRCP Paediatrician

Glynis A Dent Grad Cert Diabetes Education, Grad Cert Human Nutrition Diabetes Educator

Martin J Kelly MB BS, FACRRM, PhD Medical Officer

Kira Kranzusch MB BS, FRACP, Paediatrician

Louise J Maple-Brown MB BS, FRACP, PhD Senior Research Fellow, and Head of

Endocrinology

Victor Nossa MB BS, FRACP, FAFPHM Paediatrician and Program Leader, Child and Youth Health ${ }^{9}$

Martin Silin $M D$, FRACP Professor of Paediatric Endocrinology ${ }^{10}$

Ashim K Sinha MB BS, MD, FRACP, Director of Diabetes and Endocrinology"

Monique L Stone MB BS, FRACP, MD

Paediatrician and Paediatric

Endocrinologist, ${ }^{8}$ and Senior Lecturer ${ }^{12}$

Sarah J Wren MHSc (Nursing), Grad Cert Diabetes Education Diabetes Educator

1Baker IDI Central Australia, Alice Springs, NT.

2 Centre for Adolescent Health, Royal Children's Hospital, Melbourne, VIC

3 Baker IDI Heart and Diabetes Institute, Melbourne, VIC
I he Baker IDI Heart and Diabetes Institute convened a group of key clinicians, policymakers and researchers (included as authors) to consider the actions that need to be taken to address type 2 diabetes mellitus (T2DM) in Australian Indigenous (Aboriginal or Torres Strait Islander) children and adolescents. This article provides a clinically focused summary of the recommendations for diagnosing, screening for, managing and preventing T2DM among Australian Indigenous children and adolescents living in rural and remote settings. These recommendations are supported by evidence graded as follows: high-quality evidence (grade A evidence), intermediate-quality evidence (grade B evidence) or consensus (grade $\mathrm{C}$ evidence). The major recommendations are shown in Box 1.

\section{Background}

Indigenous Australians experience a disproportionately high rate of T2DM. The most striking features of this epidemic include the excess risk among those living in remote settings and the premature age of onset. ${ }^{1}$ Despite data being limited, T2DM among Indigenous children and adolescents appears to be increasing in incidence and the burden is much greater than that experienced by nonIndigenous young people. ${ }^{2-4}$ Indigenous children and adolescents with T2DM typically have a family history of T2DM and are overweight or obese, and may have signs of hyperinsulinism such as acanthosis nigricans. ${ }^{2,5}$ Onset of T2DM is usually during early adolescence and patients are often asymptomatic at presentation. ${ }^{2}$ These findings are similar to data from the United States. ${ }^{6}$ Data on comorbidities at diagnosis are lacking and may be a reflection of poor screening. ${ }^{7}$ However, the prevalence of microvascular and macrovascular complications and mortality associated with T2DM among Indigenous children and adolescents is significant (grade C evidence). ${ }^{8}$

The determinants of risk for T2DM in children and adolescents are complex. Intrauterine exposures, including diabetes during pregnancy, can modify the expression of genes in the fetus related to carbohydrate metabolism, ${ }^{9}$ and gestational diabetes is prevalent among Indigenous mothers; ${ }^{10}$ obesity, physical inactivity, genetic predisposition and socioeconomic status have been implicated; ${ }^{11}$ and the social determinants of health play a central role. ${ }^{12}$

T2DM during childhood and adolescence can have significant implications for the young person, their family and their community. ${ }^{13}$ It can add considerable strain to
Summary

The burden of type 2 diabetes mellitus (T2DM) among Indigenous children and adolescents is much greater than in non-Indigenous young people and appears to be rising, although data on epidemiology and complications are limited. Young Indigenous people living in remote areas appear to be at excess risk of T2DM.

- Most young Indigenous people with T2DM are asymptomatic at diagnosis and typically have a family history of T2DM, are overweight or obese and may have signs of hyperinsulinism such as acanthosis nigricans. Onset is usually during early adolescence.

- Barriers to addressing T2DM in young Indigenous people living in rural and remote settings relate to health service access, demographics, socioeconomic factors, cultural factors, and limited resources at individual and health service levels.

We recommend screening for T2DM for any Aboriginal or Torres Strait Islander person aged $>10$ years (or past the onset of puberty) who is overweight or obese, has a positive family history of diabetes, has signs of insulin resistance, has dyslipidaemia, has received psychotropic therapy, or has been exposed to diabetes in utero.

Individualised management plans should include identification of risk factors, complications, behavioural factors and treatment targets, and should take into account psychosocial factors which may influence health care interaction, treatment success and clinical outcomes.

Preventive strategies, including lifestyle modification, need to play a dominant role in tackling T2DM in young Indigenous people.

the health system and have a negative influence on the developmental trajectory of young people. ${ }^{14}$ Responding to the growing number of children and adolescents with T2DM, particularly those living in rural and remote settings, represents a complex challenge for the Australian health care system.

\section{Diagnosis}

Criteria for diagnosis in Indigenous children and adolescents are shown in Box 2. While diagnosis of T2DM can be made based on random blood glucose levels (repeated or in combination with symptoms), confirmation of the diagnosis should be made with a fasting venous blood glucose test, in conjunction with other 
1 Major recommendations for addressing T2DM in Indigenous children and adolescents

Epidemiology and public health

- Improved systems for monitoring the evolution of T2DM in Indigenous children and adolescents need to be established.

- In parallel, registers of diabetes during pregnancy should be established.

\section{Classification and diagnosis}

- Standardised methodology, classification and diagnostic criteria should be used in all studies of T2DM in Indigenous children and adolescents.

- All children and adolescents with newly diagnosed diabetes should have blood or urinary ketone levels checked to guide initial management of the diabetes. Where testing is available, levels of autoantibodies and C-peptide should be measured.

Screening and treatment

- Targeted screening of Indigenous Australian children and adolescents at risk of diabetes should be performed. Every Indigenous child should be screened to determine whether they are overweight.

- Opportunities to provide health screening for Indigenous children and adolescents should be maximised. Clinics should be made as adolescent friendly as possible and young people should be offered a comprehensive health assessment at each clinical encounter.

- Screening for complications should be undertaken at the time of diagnosis and annually thereafter for children and adolescents with T2DM.

- Children and adolescents on insulin therapy should have access to 24-hour emergency care.

- Health systems should be adequately resourced to respond to the demands of screening and follow-up.

- Management plans for treating Indigenous children and adolescents with T2DM should be individualised, taking into account psychosocial factors. Indigenous health workers and patients' families should be involved, respecting the right to confidential health care for older adolescents.

Prevention

- Greater resources and effort should be put into developing more effective strategies to prevent childhood obesity and T2DM.

Strategies for the prevention of childhood T2DM need to involve program activity at government and societal levels, target the social determinants of health, and support individual change.

- Programs to prevent obesity need to address barriers to physical activity and food security, invest in improving maternal and child health (particularly maternal nutrition and breastfeeding, and treatment of gestational diabetes), and pay greater attention to the conditions in which children spend the first years of their lives.

T2DM = type 2 diabetes mellitus.

baseline investigations (grade $\mathrm{C}$ evidence). Thirst is not unusual in hot and dry climates, but the combination of marked polydipsia and polyuria (particularly nocturnal) is suggestive of diabetes and should lead to screening (grade C evidence).

The definitions listed in Box 2 relate to laboratorymeasured values. Point-of-care capillary blood glucose levels have been found to be highly concordant with laboratory measured blood glucose levels in remote Australia; a random point-of-care capillary sample with blood glucose level $\geqslant 12.2 \mathrm{mmol} / \mathrm{L}$ is equivalent to a laboratorymeasured venous sample with blood glucose level $\geqslant 11.1$ $\mathrm{mmol} / \mathrm{L}$ (grade B evidence). ${ }^{16}$
2 Criteria for diagnosing T2DM in Indigenous children and adolescents $^{15}$

- Random laboratory-measured* venous BGL $\geqslant 11.1 \mathrm{mmol} / \mathrm{L}$ and symptoms of both polyuria and polydipsia (particularly when these symptoms are nocturnal)

or

- Fasting laboratory-measured venous $B G L \geqslant 7.0 \mathrm{mmol} / \mathrm{L}$ (fasting is defined as no intake of calories for at least 8 hours)

- Random laboratory-measured* plasma BGL $\geqslant 11.1 \mathrm{mmol} / \mathrm{L}$ on at least two separate occasions

BGL = blood glucose level. T2DM = type 2 diabetes mellitus. * These definitions relate to laboratory-measured values. Point-of-care capillary BGLs have been found to be highly concordant with laboratory measured BGLs in remote Australia; a random point-of-care capillary sample with $B G L \geqslant 12.2 \mathrm{mmol} / \mathrm{L}$ is equivalent to a laboratory-measured venous sample with $B G L \geqslant 11.1 \mathrm{mmol} / \mathrm{L}$ (grade $B$ evidence). ${ }^{16}$

Oral glucose tolerance tests (OGTTs) can be impractical in certain circumstances, particularly in rural and remote settings where health resources are limited. An OGTT should not be performed if diabetes can be diagnosed using fasting, random or postprandial criteria as excessive hyperglycaemia can result. ${ }^{15}$ OGTTs should not routinely be used to diagnose T2DM in Indigenous children and adolescents in rural and remote settings (grade $\mathrm{C}$ evidence). If there is doubt about the diagnosis, referral should be made to a paediatrician or endocrinologist for an OGTT (grade C evidence).

The use of point-of-care glycated haemoglobin $\left(\mathrm{HbA}_{1 \mathrm{c}}\right)$ testing to diagnose diabetes in adults is recommended, and is advantageous in remote settings. ${ }^{17}$ However, no clear recommendations are yet available for children and adolescents, and recent data has shown $\mathrm{HbA}_{1 \mathrm{c}}$ testing to be a poor screener for dysglycaemia and diabetes in children and adolescents. ${ }^{18} \mathrm{HbA}_{1 \mathrm{c}}$ testing should therefore not be used for the diagnosis of T2DM in Indigenous children and adolescents (grade B evidence).

All children and adolescents with suspected or newly diagnosed diabetes should have blood or urinary ketone levels checked. The presence of ketones requires immediate transfer to hospital and likely management with insulin until the diagnosis is clarified by further testing (grade $\mathrm{C}$ evidence).

\section{Screening}

Recent international guidelines recommend that screening of asymptomatic young people for T2DM is likely to have a low yield. However, in populations with a high diabetes prevalence, clinicians may favour screening while awaiting more information on effective screening strategies. ${ }^{15,19}$

At present, the documented burden of T2DM among Indigenous children and adolescents does not justify population screening. In this context, screening should therefore be aimed at enhancing case detection and focused on Indigenous children and adolescents with features suggestive of an elevated risk of T2DM.

We recommend that any Indigenous Australian over the age of 10 years (or past the onset of puberty) who is overweight or obese, has a positive family history of diabetes, has signs of insulin resistance, has dyslipidaemia, has received psychotropic therapy, or has been exposed to
4 Alice Springs Hospital Alice Springs, NT.

5 Pukatja Clinic, Nganampa Health Council Alice Springs, NT.

6 Central Australian Remote Health Alice Springs, NT.

7 Menzies School of Health Research, Darwin, NT.

8 Royal Darwin Hospital, Darwin, NT.

9 Department of Health Darwin, NT.

10 University of Sydney Sydney, NSW.

11 Cairns Base Hospital Cairns, QLD.

12 Flinders University, Darwin, NT.

alex.brown@

bakeridi.edu.au

MJA 2012; 197: 32-36 doi: 10.5694/mjal2.10036 
3 Barriers to managing type 2 diabetes mellitus in Indigenous children and adolescents living in rural and remote settings

Health seeking (grade $B$ evidence)

- Limited contact with health services, relating to: perceived "health" despite significant morbidity ${ }^{21}$ clinics not being adolescent friendly ${ }^{22}$

Demographic (grade B evidence)

- Remoteness, limited telecommunication facilities, poor school attendance, poor socioeconomic health, no fixed address $^{23}$

Sociocultural (grade $\mathrm{C}$ evidence)

- Potential shame of diagnosis ${ }^{24}$

- Acceptance of poor health status (by individuals and the health system)

- Many competing health needs

Physical resources (grade $B$ evidence)

- Limited resources for lifestyle modification ${ }^{25}$

- Food insecurity ${ }^{26}$

Clinic resources - physical (grade $\mathrm{C}$ evidence)

- Inaccessibility of essential resources (such as glycated

haemoglobin testing) in many remote clinics $^{27}$

- Misplaced or broken blood glucose meters

- Lack of infrastructure to start, maintain or safely store insulin

Clinic resources - staffing (grade $\mathrm{C}$ evidence)

- Understaffing and high staff turnover ${ }^{28}$

- Overburdened clinic staff due to acute crisis care 29

- Limited and poorly coordinated visiting specialist services

diabetes in utero should be offered screening for T2DM (grade $\mathrm{C}$ evidence). The method of screening for Indigenous children and adolescents at risk of T2DM is to test random blood glucose level in a clinical setting where adequate interpretation, management and follow-up will be provided (see Appendix 1; online at mja.com.au). Those who screen positive almost certainly have T2DM. The significance of this diagnosis and its impact should not be underestimated. Patients should be provided with the time to understand and question the diagnosis, the further testing and the required treatments. If appropriate, support from family and Indigenous health workers should be sought (grade B evidence). ${ }^{20}$

\section{Management}

Challenges in health care delivery in remote areas: Limited resources at the individual, community and health care levels pose significant challenges to managing T2DM in rural and remote settings (Box 3). Food insecurity and socioeconomic disadvantage can limit opportunities for lifestyle modification. ${ }^{25,26}$ Health systems are often overstretched, responding to high rates of chronic disease in adults; they may be less than adequately staffed and may lack basic resources. ${ }^{27}$ The combination of these factors can result in poor and infrequent follow-up for Indigenous young people with T2DM, limited response to persistent hyperglycaemia, reluctance to commence and continue insulin therapy, and limited screening for complications (grade $\mathrm{C}$ evidence).

Engaging Indigenous young people: Engaging young people with clinical services to screen for, identify and manage T2DM is more likely if the services are accessible, demonstrate equity in service delivery, are acceptable and appropriate for the needs and cultural norms of the community, and are comprehensive and effective. ${ }^{22}$ Confidentiality is an essential component of providing health care to young people, particularly in small isolated communities. A young person who does not attend his or her clinic appointment may still care about their newly diagnosed diabetes, and non-attendance should therefore trigger further engagement with all necessary social and family support (grade C evidence).

Initial management: Initial management of T2DM is determined by symptoms, severity of hyperglycaemia, and the presence or absence of ketones and ketoacidosis (summarised in Appendix 2; online at mja.com.au). ${ }^{15}$ Insulin therapy may be initially required for stabilisation in the setting of significant hyperglycaemia and ketosis, even in the absence of ketoacidosis. ${ }^{15}$ Symptomatic patients, particularly those with vomiting and dehydration, should be monitored closely because their condition could deteriorate rapidly.

Psychosocial health: Routine psychosocial assessment promotes recognition of and response to psychosocial comorbidities, and provides appreciation of the context in which lifelong management will need to be established and maintained..$^{30}$ Psychosocial health is a critical consideration in establishing a care plan (Box 4). Indigenous health workers play an essential role in the management team, especially in addressing psychosocial health, and should be engaged at all stages of management. ${ }^{20}$

Lifestyle modification: When managing T2DM, the primary emphasis should be on lifestyle modification. ${ }^{19}$ It is essential to engage the family in lifestyle modification, respecting the right to confidential health care for older adolescents. Engaging the family increases the likelihood of the young person modifying his or her behaviour, and may also reduce the risk of diabetes and its complications within an at-risk family (grade $\mathrm{C}$ evidence).

Blood glucose monitoring: The performance and frequency of self-monitoring of blood glucose levels should be individualised, taking into account factors identified during management planning. ${ }^{15}$ Once glycaemic control has been achieved, several fasting values per week and daily postprandial measures (taken after the largest meal) are satisfactory given the values remain in the target range. ${ }^{15}$ Young people treated with insulin require more frequent testing to monitor for hypoglycaemia.

$\mathrm{HbA}_{1 \mathrm{c}}$ levels should be tested quarterly (grade $\mathrm{C}$ evidence). International guidelines recommend an $\mathrm{HbA}_{1 \mathrm{c}}$ target of $<7.5 \%$ for all paediatric age groups and $<7 \%$ for adolescents approaching adulthood. ${ }^{15}$ The Central Australian Rural Practitioners Association guidelines recommend, for adults, a target of $<7 \%$ for T2DM. ${ }^{34}$ For simplicity, an $\mathrm{HbA}_{1 \mathrm{c}}$ target of $<7 \%$ is recommended for Indigenous children and adolescents with T2DM (grade $\mathrm{C}$ evidence).

Oral hypoglycaemic agents and insulin: Currently, metformin and insulin are the only hypoglycaemic agents approved for children and adolescents with T2DM; their use is shown in Appendix $2 .{ }^{15}$ Dosing of these medications should follow local protocols; for children $<14$ years of age, this should be discussed with a paediatrician (grade C 
4 Care plan for Indigenous children and adolescents with type 2 diabetes mellitus, adapted from guidelines produced by the International Diabetes Federation, International Society for Pediatric and Adolescent Diabetes and Asian-Pacific Type 2 Diabetes Group ${ }^{15,19,31,32}$

Issue to address

First visit

Quarterly visit Annual visit

Target

Action if target not met

\begin{tabular}{|c|c|c|c|c|c|}
\hline \multicolumn{6}{|l|}{ Lifestyle } \\
\hline Psychosocial health & $\checkmark$ & $\checkmark$ & $\checkmark$ & $\begin{array}{l}\text { Address issues relating to home, } \\
\text { education and employment, activities, } \\
\text { drugs, depression, sexuality and } \\
\text { spirituality* }\end{array}$ & $\begin{array}{l}\text { Engage family, Indigenous health workers, social } \\
\text { services and mental health services as required }\end{array}$ \\
\hline Behavioural factors & $\checkmark$ & $\checkmark$ & $\checkmark$ & $\begin{array}{l}\text { Address SNAP: smoking, nutrition, } \\
\text { alcohol, physical activity }{ }^{33}\end{array}$ & $\begin{array}{l}\text { Engage family, Indigenous health workers, social } \\
\text { services and mental health services as required }\end{array}$ \\
\hline Diagnostic tests & $\checkmark$ & & & $\begin{array}{l}\text { Complete baseline investigations: } \\
\text { fasting BGL, autoantibodies (GAD, IA2, } \\
\text { insulin), C-peptide }\end{array}$ & Discuss with district medical officer \\
\hline \multicolumn{6}{|l|}{ Glycaemic control } \\
\hline BGL & $\checkmark$ & $\checkmark$ & $\checkmark$ & $\begin{array}{c}\text { Premeal BGL, }<7.2 \mathrm{mmol} / \mathrm{L} ; \\
\text { postmeal BGL, }<10.0 \mathrm{mmol} / \mathrm{L}\end{array}$ & $\begin{array}{l}\text { Congratulate on addressing their diabetes; do not } \\
\text { blame; consider psychosocial issues; consider } \\
\text { compliance and need to escalate treatment; } \\
\text { consider specialist advice (Appendix 2) }\end{array}$ \\
\hline $\mathrm{HbA}_{\mathrm{lc}}$ & $\checkmark$ & $\checkmark$ & $\checkmark$ & $<7 \%(<53 \mathrm{mmol} / \mathrm{mol})$ & $\begin{array}{l}\text { Congratulate on addressing their diabetes; do not } \\
\text { blame; consider psychosocial issues; consider } \\
\text { compliance and need to escalate treatment; } \\
\text { consider specialist advice (Appendix 2) }\end{array}$ \\
\hline Weight & $\checkmark$ & $\checkmark$ & $\checkmark$ & Reduce body weight & $\begin{array}{c}\text { Continue to support healthy diet and exercise, } \\
\text { engage family }\end{array}$ \\
\hline $\begin{array}{l}\text { Height, BMI, waist } \\
\text { circumference }\end{array}$ & $\checkmark$ & & $\checkmark$ & BMI < 95th centile (non-obese) & $\begin{array}{c}\text { Continue to support healthy diet and exercise, } \\
\text { engage family }\end{array}$ \\
\hline \multicolumn{6}{|l|}{ Complications screening } \\
\hline Blood pressure & $\checkmark$ & $\checkmark$ & $\checkmark$ & $\begin{array}{l}\text { Blood pressure, }<95 \text { th centile by age, } \\
\text { sex and height }\end{array}$ & Consider ACEi \\
\hline $\begin{array}{l}\text { Fasting lipids (total cholesterol, } \\
\text { HDL, LDL, triglycerides) }\end{array}$ & $\checkmark$ & $?$ & $\checkmark$ & $\begin{array}{l}\mathrm{LDL},<2.6 \mathrm{mmol} / \mathrm{L} ; \\
\text { triglycerides, }<1.7 \mathrm{mmol} / \mathrm{L}\end{array}$ & Diet, lifestyle, consider statins \\
\hline $\begin{array}{l}\text { Urea, creatinine, electrolytes, } \\
\text { ACR, microalbuminuria if } \\
\text { possible }\end{array}$ & $\checkmark$ & $?$ & $\checkmark$ & $\begin{array}{l}\text { Refer to local laboratory reference } \\
\text { intervals }\end{array}$ & $\begin{array}{c}\text { Discuss with specialist; treat hypertension and } \\
\text { albuminuria with ACEi }\end{array}$ \\
\hline $\begin{array}{l}\text { Eyes: visual acuity, dilated } \\
\text { fundoscopy }\end{array}$ & $\checkmark$ & & $\checkmark$ & Monitor and treat retinopathy & Refer to ophthalmologist \\
\hline Feet: pulses and neuropathy & $\checkmark$ & & $\checkmark$ & $\begin{array}{l}\text { Monitor and treat neuropathy and } \\
\text { macrovascular complications }\end{array}$ & Refer to specialist and podiatrist \\
\hline Liver function & $\checkmark$ & $?$ & $\checkmark$ & $\begin{array}{l}\text { Refer to local laboratory reference } \\
\text { intervals }\end{array}$ & $\begin{array}{l}\text { Maximise glycaemic control and weight loss for } \\
\text { NAFLD; refer to specialist }\end{array}$ \\
\hline Obstructive sleep apnoea & $\checkmark$ & $?$ & $\checkmark$ & No obstructive symptoms & $\begin{array}{c}\text { Refer for sleep study if obstructive sleep apnoea } \\
\text { suspected }\end{array}$ \\
\hline Opportunistic health screening & $\checkmark$ & $\checkmark$ & $\checkmark$ & \multicolumn{2}{|c|}{$\begin{array}{l}\text { Consider sexual health (sexually transmitted infections, contraception, and PCOS } \\
\text { screening in patients with oligomenorrhoea, acne or hirsutism), immunisation, mental } \\
\text { health, nutrition (anaemia), and other health needs }\end{array}$} \\
\hline \multicolumn{6}{|c|}{ 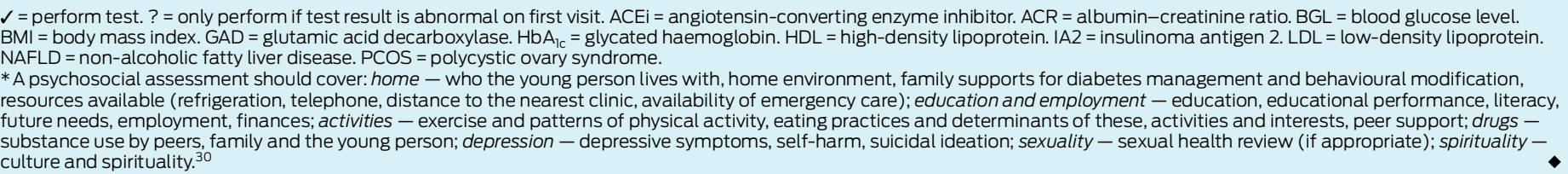 } \\
\hline
\end{tabular}

evidence). Barriers to self-management should be addressed at each visit.

In commencing insulin therapy, close follow-up is required to titrate the dose; this may be over the telephone or in person. All children and adolescents starting on insulin therapy should have access to emergency care and, in particular, should be educated about the symptoms, signs and management of hypoglycaemia (grade $\mathrm{C}$ evidence). As diet is often erratic and access to emergency care for hypoglycaemia may be limited, long-acting basal insulin may be the best initial choice (grade $\mathrm{C}$ evidence).

Screening for complications and comorbidities: Microvascular complications and risk factors for cardiovascular disease or actual macrovascular complications may be present at diagnosis of T2DM among children and adolescents. ${ }^{13}$ As a result, screening for complications should be undertaken at diagnosis and annually thereafter (Box 4). Screening for complications such as renal disease, hypertension and retinopathy are of utmost importance in this high-risk group (grade $\mathrm{C}$ evidence).

Specialist referral: Referral to an endocrinologist (or physician with experience in managing diabetes) and diabetes educator is recommended at diagnosis and again if glycaemic control remains suboptimal despite lifestyle changes and metformin and insulin therapy (grade $\mathrm{C}$ evidence).

Treatment targets: Achieving the goals of treatment (Box 4) can be a daunting task, and may take some time to achieve. Any small improvement towards these targets should be encouraged. 
of the Commission on Social Determinants of Health. Geneva: World Health Organization, 2008. http://www.who.int/social_determinants/thecommission/ finalreport/en/index.html (accessed May 2012).

Given the relatively poor prognosis for many young people once a diagnosis of T2DM is made and the continuing increase in prevalence of T2DM, effective prevention needs to play a dominant role in tackling this key health problem. Planned interventions need to be practical and undertaken with due attention to the demographic, social and cultural needs of the Indigenous community. They should involve: - consultation and engagement of communities and those "at the front line"

- investment in programs that address social determinants of health ${ }^{12}$

- measurement of the problem and evaluation of action

- appropriate funding and resources.

The immediate benefits of investing in lifestyle modification for individuals at risk of T2DM should not be overlooked. While some clinicians may elect to treat adolescents with obesity and metabolic syndrome (particularly those with abnormal glucose tolerance) with metformin, there needs to be an improved evidence base, and outcome data, before this can be recommended as a strategy. ${ }^{35}$ In adults, metformin therapy decreases progression of impaired glucose tolerance to T2DM, but lifestyle modification and a small amount of weight loss (average of $5.6 \mathrm{~kg}$ ) is a more effective intervention. ${ }^{36}$

Engaging communities and working with Indigenous health workers is vital for preventing T2DM, not only to better identify those at risk but also to ensure that prevention efforts are appropriate.

Acknowledgements: This project was funded by a private donor. We acknowledge Malcolm King (Scientific Director, Institute of Aboriginal Peoples' Health, Canadian Institutes of Health Research) and Alexandra King (Registrar in Internal Medicine, (anada), who were observers at the workshop.

Competing interests: No relevant disclosures.

Provenance: Not commissioned; externally peer reviewed.

1 Minges KE, Zimmet P, Magliano DJ, et al. Diabetes prevalence and determinants in Indigenous Australian populations: a systematic review. Diabetes Res Clin Pract 2011; 93: 139-149.

2 Maple-Brown LJ, Sinha AK, Davis EA. Type 2 diabetes in indigenous Australian children and adolescents. J Paediatr Child Health 2010; 46: 487-490.

3 Craig ME, Femia G, Broyda V, et al. Type 2 diabetes in Indigenous and nonIndigenous children and adolescents in New South Wales. Med J Aust 2007; 186: 497-499.

4 McMahon SK, Haynes A, Ratnam N, et al. Increase in type 2 diabetes in children and adolescents in Western Australia. Med J Aust 2004; 180: 459-461.

5 Sinha A, O'Rourke S, Yarker J, et al. Type 2 diabetes in children and adolescents in the Indigenous communities of Far North Queensland. Diabetes Res Clin Pract 2000; 50: 126.

6 Copeland KC, Zeitler P, Geffner M, et al. Characteristics of adolescents and youth with recent-onset type 2 diabetes: the TODAY cohort at baseline. J Clin Endocrinol Metab 2011; 96: 159-167.

7 Shield JP, Lynn R, Wan KC, et al. Management and 1 year outcome for UK children with type 2 diabetes. Arch Dis Child 2009; 94: 206-209.

8 Dart AB, Sellers EA, Martens PJ, et al. High burden of kidney disease in youthonset type 2 diabetes. Diabetes Care 2012; 35: 1265-1271.

9 Dabelea D, Pettitt DJ. Intrauterine diabetic environment confers risks for type 2 diabetes mellitus and obesity in the offspring, in addition to genetic susceptibility. J Pediatr Endocrinol Metab 2001; 14: 1085-1091.

10 Ishak M, Petocz P. Gestational diabetes among Aboriginal Australians: prevalence, time trend, and comparisons with non-Aboriginal Australians. Ethn Dis 2003; 13: 55-60.

11 Alberti G, Zimmet P, Shaw J, et al. Type 2 diabetes in the young: the evolving epidemic: the international diabetes federation consensus workshop. Diabetes Care 2004; 27: 1798-1811.

12 Commission on Social Determinants of Health. Closing the gap in a generation: health equity through action on the social determinants of health. Final Report
13 Pinhas-Hamiel O, Zeitler P. Acute and chronic complications of type 2 diabetes mellitus in children and adolescents. Lancet 2007; 369: 1823-1831.

14 United Nations Children's Fund. The state of the world's children 2011. Adolescence: an age of opportunity. New York: UNICEF, 2011. http:// www.unicef.org/sowc2011 (accessed May 2012).

15 International Diabetes Federation. Global IDF/ISPAD guideline for diabetes in childhood and adolescence. Brussels: IDF, 2011. http://www.idf.org/sites/ default/files/Diabetes\%20in\%20Childhood\%20and\%20Adolescence\%20 Guidelines_0.pdf (accessed May 2012).

16 Marley JV, Davis S, Coleman K, et al. Point-of-care testing of capillary glucose in the exclusion and diagnosis of diabetes in remote Australia. Med J Aust 2007; 186: 500-503.

17 World Health Organization. Use of glycated haemoglobin (HbAlc) in the diagnosis of diabetes mellitus. Geneva: WHO, 2011. http://www.who.int/ diabetes/publications/diagnosis_diabetes2011/en/index.html (accessed May 2012).

18 Kester LM, Hey H, Hannon TS. Using hemoglobin Alc for prediabetes and diabetes diagnosis in adolescents: can adult recommendations be upheld for pediatric use? J Adolesc Health 2012; 50: 321-323.

19 Rosenbloom AL, Silverstein JH, Amemiya S, et al. Type 2 diabetes in children and adolescents. Pediatr Diabetes 2009; 10 Suppl 12: 17-32.

20 Chang AB, Taylor B, Masters IB, et al. Indigenous healthcare worker involvement for Indigenous adults and children with asthma. Cochrane Database Syst Rev 2010; (5): CD006344.

21 Australian Institute of Health and Welfare. Young Australians: their health and wellbeing 2011. Canberra: AlHW, 2011. (AlHW Cat. No. PHE 140.) http:// www.aihw.gov.au/publication-detail/?id=10737419261 (accessed May 2012).

22 World Health Organization. Adolescent friendly health services: an agenda for change. Geneva:WHO, 2002. http://whqlibdoc.who.int/hq/2003/WHO_FCH_ CAH_02.14.pdf (accessed May 2012).

23 Australian Bureau of Statistics. Population characteristics, Aboriginal and Torres Strait Islander Australians, 2006. Canberra: ABS, 2010. (ABS Cat. No. 4713.0.) http://www.abs.gov.au/ausstats/abs@.nsf/mf/4713.0 (accessed May 2012).

24 Dussart F. Diet, diabetes and relatedness in a central Australian Aboriginal settlement: some qualitative recommendations to facilitate the creation of culturally sensitive health promotion initiatives. Health Promot J Austr 2009; 20: 202-207.

25 Edwards N, Coffin J, Lower T. Physical activity amongst Aboriginal youth in Geraldton: a photovoice project. Aboriginal and Islander Health Worker Journal 2005; 29: 26-27.

26 Brimblecombe JK, O'Dea K. The role of energy cost in food choices for an Aboriginal population in northern Australia. Med J Aust 2009; 190: 549-551.

27 Bailie R, Si D, Dowden M, et al. Improving organisational systems for diabetes care in Australian Indigenous communities. BMC Health Serv Res 2007; 7: 67.

28 Coffin J. Rising to the challenge in Aboriginal health by creating cultural security. Aboriginal and Islander Health Worker Journal 2007; 31: 22-24.

29 Peiris D, Wirtanen C, Hall J. Aeromedical evacuations from an east Arnhem Land community 2003-2005: the impact on a primary health care centre. Aust J Rural Health 2006; 14: 270-274.

30 Royal Australasian College of Physicians. Routine adolescent psychosocial health assessment - position statement. Sydney: RACP, 2008. http:// www.racp.edu.au/page/paed-policy (accessed May 2012).

31 Asian-Pacific Type 2 Diabetes Policy Group. Type 2 diabetes: practical targets and treatments. 3rd ed. Sydney: Health Communications Australia and In Vivo Communications, 2002.

32 Donaghue KC, Chiarelli F, Trotta D, et al. Microvascular and macrovascular complications associated with diabetes in children and adolescents. Pediatr Diabetes 2009; 10 Suppl 12: 195-203.

33 Royal Australian College of General Practitioners. Smoking, nutrition, alcoho and physical activity (SNAP): a population health guide to behavioural risk factors in general practice. Victoria: RACGP, 2004. http://www.racgp.org.au/ guidelines/snap (accessed May 2012)

34 Central Australian Rural Practitioners Association. CARPA standard treatment manual. Alice Springs: CARPA, 2009

35 Sabin MA, Magnussen CG, Juonala M, et al. The role of pharmacotherapy in the prevention and treatment of paediatric metabolic syndrome - implications for long-term health: part of a series on Pediatric Pharmacology, guest edited by Gianvincenzo Zuccotti, Emilio Clementi, and Massimo Molteni. Pharmacol Res 2012; 65: 397-401.

36 Knowler WC, Barrett-Connor E, Fowler SE, et al. Reduction in the incidence of type 2 diabetes with lifestyle intervention or metformin. N Engl J Med 2002; 346: 393-403. 